erysipelas, who, after a lingering first labour of twins, succeeded by considerable flooding, appeared doing well. On the 11th she had a rigor, succeeded by very profuse perspiration, rapid pulse, and tympanitic abdomen, without pain on pressure. At first these symptoms seemed to yield to treatment, but diarrhoea supervened, and she died early on the morning of the 15th. On this day he was called to a patient three miles distant from the preceding one; it was her fourth child. She had an easy labour, and was left comfortable in every respect. On the morning of the 16 th she complained of a fixed pain in the lower part of the abdomen, without any degree of tension, but increased on pressure, with quick feeble pulse, anxious countenance. \&c. No treatment was of the slightest avail; she gradually declined, and died at noon of the 18th.

Dr. Hughes could not now fail to recognize the source of this fatality, and also the distressing fact that he had been the vehicle of the contagion, as no other possible communication could have taken place between the affected parties, and no similar cases had occurred to any other medical man in the neighbourhood. On the 8th of October he had attended a midwifery patient, who did well, and thus on the occurrence of his first fatal case he was scarcely prepared to suspect its origin.

That erysipelas does not at aly times generate this contagious poison is certain; for, independent of other authorities, Dr. Hughes, in a practice of nineteen years, has attended many more severe cases than those now reported, with impunity, and has seen erysipelas in the lying-in room, where the circumstances of the family rendered separation impossible, without any ill effects.

Regarding the power of generating puerperal fever as an occasional effect of erysipelas, under what circumstances should we most dread its baneful influence?

From the earliest periods of medicine, variable and unseasonable weather has been considered prejudicial to the recovery of lying-in women, but later experience has shown the impossibility of attaching certain importance to any such atmospheric conditions. We have it reported, in respect to the epidemic at $\mathbf{L a}$ Maternité, in Paris, in 1829, that the puerperal fever then raging prevailed in its greatest degree during cold dry weather, during dry temperate weather, and during moist temperate weather, while at other seasons of the year the same kinds of weather did not render the disease more frequent than usual. Its malignity at one time, as reported by Dr. John Clarke, has been checked by a sharp frost, while more commonly warm weather has favoured its decline, and cold weather its increase.

Nor does the consideration of coexistent epidemics throw much more light on the subject. Undoubtedly, on many occasions, as at Aberdeen, Leeds, and Aylesbury, and more frequently in London and Dublin, erysipelas has prevailed, at the same time as puerperal fever. Still more frequently have epidemic fevers, of a typhoid type, been the concomitant diseases; but yet so many instances have occurred, especially in country practice, in which either malady has existed independently of the other, that we cannot venture to deduce any certain practical conclusions from their occasional coexistence. When the cases Dr. Hughes has now reported occurred, low typhoid fever was prevalent in the neighbourhood of Mold, and some few cases of erysipelas of the head and face, but of no serious character, had come under treatment. In the year 1847 he attended very many more, ill of both diseases, and experienced no injurious effects in his midwifery practice.

As the preceding observations are intended to show that the causes which favour the origin of puerperal fever from the contagion of erysipelas are as yet obscure, he can only repeat the recommendation to medical men when attending such cases, carefully to watch the recoveries in the lying-in room, and at the same time strictly to observe those precautions which their duties, and the well-doing of their patients, peremptorily demand of them.

Mold, June 12, 1850.

\section{ON THE}

\section{STRUCTURE OF THE MEMBRANA TYMPANI IN THE HUMAN EAR.*}

Bx JOSEPH.TOYNBEE, Esa., F.R.S.

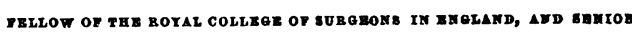
GUBGEN TO ST, GEORGE'S AKD ST. JAMES'B DIMPAKSARY, LONDOK:

IN this paper the membrani tympani is described as consisting of the following layers, which are quite distinct from each other, both as regards their structure and functions :-

1. Epidermis.

2. The proper fibrous layer, composed of,-

$a$ The lamina of radiating fibres.

$b$ The lamina of circular fibres.

3. Mucous membrane.

One of the principal objects of the paper is to describe the structure and functions of the fibrous laminæ. Since the time of Sir Everard Home, who pronounced the layer of radiating fibres to be muscular, anatomists have differed in their views of the nature of the fibrous element of the membrana tympani. The lamina of radiating fibres, the outer surface of which is covered by the epidermis, is described as continuous with the periosteum of the external meatus. With the exception of the uppermost fibres which, on account of their being somewhat flaccid, have been considered as a separate tissue, under the name of "membrana flaccida," the radiate layer is composed of fibres which extend from the circular cartilaginous ring to the malleus, and they interlace in their course. These fibres are from 4000 to 5000 parts of an inch in breadth.

The lamina of circular fibres consists of circular fibres which are firm and strong towards the circumference, but very attenuated towards the centre. These

- The paper, of which a short abstract is here publiahed, was read at the Royal society, on the 20th of June. 
fibres are so attached and arranged as to form a layer of membrane which, in a quiescent state, is saucer-shaped.

The fibres composing the circular, are smaller than those of the radiate lamina, being from 6000 to 10000 parts of an inch in breadth.

The facts that appear to be adverse to the idea of the fibres of either layer being muscular are:-

1st. The absence of distinct nuclei in the fibres.

2nd. Their great denseness and hardness.

It is next shown that the four laminæ forming the membrana tympani are continuous with other structures, of which they appear to be mere modifications, and that not one is proper to the organ.

The tensor tympani ligament, which had not been previously noticed by anatomists, is particularly described; it is attached externally to the malleus, close to the insertion of the tensor tympani muscle, and internally to the cochleariform process.

The latter part of the paper is occupied by observations on the functions of the fibrous laminæ and of the tensor ligament of the membrana tympani; and it is shewn that by these tr.o antagonistic forces, the one tending to draw the membrana tympani inwards, the other outwards, this organ is maintained in a state of moderate tension, and is always in a condition to receire ordinary sonorous undulations.

\section{THOUGHTS ON PASSING EVENTS.}

\section{BY AMBIDEXTER.}

OU R A S S OCIATION.

Certain recent "checks" in the Medical Reform chase have tended greatly to develop the importance of the Provincial Medical and Surgical Association, for although the weight of our two thousand members cannot be said to have stayed the hand of the Secretary of State, yet, it is evident, the judicious Minister will prepare no measure which shall be distasteful to a body of men so large and influential.

The consideration of this severe impediment in the path of the Reformers - this barrier of common sense before the eyes oi Government, has led us into a more critical analysis of the laws of our organization, than a cursory glance at the objects to which the attention of the members of the Association is commonly directed, would shew. That there is a hidden keystone, as it were, to the arch which supports our order is certain, for it is scarcely conceivable that so large a number of men, in actual practice, prealuded by their calling, from frequent personal communication, possessed of all shades of political, religious, and medical opinion, and dragged by their destiny to mortal combat with disease in every variety of class and temperament, from the patrician hall and cathedral cloister, down to the union house and hovel on the heath, should continue of one mind in a confederacy, the chief good of which is a secret to the superficial observer, and a blank to the thoughtless, unless some latent power were at work to bend such motley spirits to one will.
Lawyer: of all denominations ar sem to mee and unite themselves into one body by the forse of their common secular interests. The clergy have one head, one faith, and a singleness of purpose before them. Soldiers and sailors are in themselves a clan. The doctors alone are divided. The immediate advantages of universal co-operation to their professional-i. e., worldly-advancement are difficult to be seen, and therefore, "everyone for himself" is the earliest oracle in practice. Yet a band of two thousand brothers, without actually separating themselves from the rest, have tacitly agreed to act on a set of given principles, which, viewed from without, have no worldly attractions to recommend them, and are no test of their individual success either in science or fortune. What, then, is the cement which for nearly twenty years has kept together this structure, and is daily adding to its strength ? We proceed to address ourselves to the solution of this problem, and to endeavour to demonstrate the one element of concord which pervades our social existence.

The common principles which govern good taste, in the highest sense of that word, we believe to be the great power which directs our commonwealth. There is a silent agreement among the members of our Association concerning the treatment proper to be pursued in their dealings with questions of philosophy and ethics ; for by a slight effort of the imagination we may recognize a conmon measure by which controversies which relate to the actions and manners of men are determined among us; and the very duration of our system will serve to shew that this consent is not the result of an arbitrary or casual theory which has been called up by some one master mind, to perish with its author, but is the natural work of certain uniform principles operating on the taste of a refined Society. Moreover, it is probable that the free exercise of these principles, which are the growth of education, could only be found in the provinces of England. The metropolis is a field in which action is chiefly confined to the immediate wants of the people; society is artificial and exclusive, and admits comparatively but few professional men to a participation in its best fruits; whereas, within the last quarter of a century, provincial surgeons have not only been permitted to enjoy, but it may be said, could hardly escape, the advantages of intellectual contact with the educated class of their patients; and this privilege, combined with the general march of improvement, has established a solid groundwork of good taste, which no other state in the profession has had the opportunity, to the same extent, of holding.

Mr. Skey, the late Hunterian orator, has unwittingly called us "an amphibious link between a profession and a trade." Mr. Skey is a wag, and has, we fear, gathered his impressions of the "degeneracy" of the profession from sour grapes. He must come into the provinces to catch the infection of good manners, and see that at least the Provincial Association is actuated by the universal rules which govern gentlemen.

We have said that one common measure is observable among us in settling questions of general interest. The 